\title{
Internet questionnaire
}

This questionnaire has been prepared by Pensions in conjunction with Kevin Wesbroom, Senior Consultant at Hewitt Bacon \& Woodrow. It looks at the use made by UK occupational schemes of the Internet and associated forms of e-commerce. A summary of the results will be published in Pensions but all participants will receive a full copy of the results. Forms should be returned by Friday, 30th May.

The questionnaire should take no more than 15-20 minutes to complete. Please photocopy and return by post or fax using the details listed below. Alternatively, a copy can be found in pdf format at www.hewittbaconwoodrow.co.uk. If in doubt on how to answer any of the questions, please complete the nearest possible response and add a suitable comment in the final section of the form. If you have any queries about the questionnaire please contact:

Kevin Wesbroom

Hewitt Bacon \& Woodrow

St Olaf House

London Bridge City

London

SE1 2PE

UK

Tel: +44 (0)20 7716 7346; Fax: +44 (0)20 7716 7316;

e-mail: kevin.wesbroom@hewitt.com

or

Susan Marshall, Publishing Editor, Pensions

Tel: +44(0)20 73232916 x101;

e-mail: susan@hspublications.co.uk

\section{Ref General information}

1.1 Company name

1.2 Contact name

1.3 Contact tel. and/or e-mail

1.4 Industry sector

1.5 Approximate number of pension scheme members (Please include active members, deferreds and pensioners)
$\square \quad 0-99$
$100-499$
$1,000-4,999$
500-999
5,000-9,999
Over 10,000 
1.6 Please describe the main type of pension arrangement you offer to staff (Where there are multiple arrangements please indicate the answer that applies to the majority)

Defined benefit (eg final salary)

Defined contribution (money purchase)

Closed DB, open DC scheme

Hybrid or combination

Other (please describe below)

\section{Website details}

2.1 Do you have a dedicated website with details of your company pension arrangements?
Yes
No

2.2 Is this internet access, an intranet, or both?

(An intranet is accessible only to staff inside the company, an internet site is accessible from outside)

$\square$ Internet

$\square$ Intranet

$\square$ Both

2.3 When did you first offer a pensions website?
$\square 2003$
1999
2002
1998
2001
1997
2000
1996 or earlier

2.4 Pensions website address

2.5 Approximately how many unique visitors did the site receive last year? (If the site is less than a year old please give the annualised rate)

2.6 How can your members contact you — or each other? (Tick all that apply)

E-mail query

Telephone hotline
Online chatroom

Other (please state)

2.7 Is the website personalised to the visitor?

(Eg do visitors enter a PIN recognised by the system that tailors the information offered accordingly?)

No personalisation

Personalisation that recognises the scheme or section to which the member belongs

Some personalisation - eg offers different

information for actives, deferreds

or pensioners

Full personalisation - eg member ID which then ties back to individual details on the member record-keeping system 
2.8 Has the website won any awards for design?

2.9 Has the website been accredited by any of these bodies?

$\square$ Crystal mark

Plain English award

RNIB

Other (please state)

2.10 How much have you spent on your website?

(This would include external spend, plus your estimate of the cost of your internal resources)

\section{Information offered}

3.1 What types of benefit information are available to visitors? (Tick all that apply)

Benefit details - active members

Benefit details — deferred members
Benefit details — pensioners

Other (please state)

3.2 What types of general information are available? (Tick all that apply)

$\square$ Pensions news items

General savings information
General financial news items

Other (please state)

3.3 Scheme level information available (Tick all that apply)

Trustees' names and contacts

Trustees' report and accounts

Actuarial valuation report

Updated funding status

Employer contributions (eg SofC)

Other (please specify below)
Investment manager names (DB)

Investment manager objectives (DB)

Investment manager performance (DB)

$\square$ Investment manager names (DC)

$\square$ Investment manager objectives (DC)

Investment manager performance (DC)

3.4 Member-specific information (Tick all that apply)

Current account value

Contribution history details

Online benefit projection tool (eg to show the impact of different investment strategies)

Other DC (please specify below)
Online pension benefit statement

AVC modellers (to show impact of paying or changing AVCs)

Online total reward statement (to show the cost of providing pensions and other employment benefits)

Other DB (please specify below)

3.5 Do you provide online reward statements to your members, ie the total value of their' retirement benefits package, including the value of their pension benefits?

Yes 
3.6 How frequently do you update the information on the pensions website?

Daily

Monthly
Weekly

Less frequently

\section{Online transactions}

4.1 To what extent can members make, or notify of, changes to their personal details online?

Change of address

Change of marital status or family details
Change nominated dependants

Other (please specify below)

4.2 To what extent can your DC members (if any) initiate transactions online?

$\square$ Change contribution level

$\square$ Change the age at which lifestyling sets in

Re-direct future contributions to

Model the effect of different types of annuity different investment fund options

Other (please specify below)

Make a switch of existing contributions

from one investment fund to another

4.3 To what extent can your members initiate benefit transactions online?

Apply to retire or otherwise draw benefits $\square$ Request transfer out of benefits

Request to purchase an annuity online (DC) $\square$ Request transfer in of benefits

Other (please specify below)

4.4 To what extent do any changes made online by the member feed straight through to the underlying record-keeping systems (as opposed to eg generating an e-mail request for action)?

$\square$ Genuine 'straight through processing'

Partially integrated
Not at all integrated

Other (please specify below) 
4.5 To what extent does your underlying record-keeping system pre-populate any membership modellers or projection tools?
Not at all
Partially
Fully pre-populated
Other (please explain below)

\section{Development of the Internet for company pension schemes}

5.1 What do you see as being the biggest advantages of Internet-based communication and administration in the pensions area? (Tick the top three)

Enhanced service to members

More effective understanding by members

More targeted communication

Greater willingness to save for retirement

Other (please specify below)
Reduced costs of administration

Better integration with other employee benefits

Ability to administer wider range of benefits

Service at a time and manner that suits members

5.2 To what extent do you think that Internet-based communication will be the means of contact with your members in five years time?

$\square$ The principal means for most members

For a majority of members

Other (please specify below)
Hardly at all

For a minority of members

5.3 What do you see as the biggest deterrents to the growth of the use of the Internet in pensions? (Tick the top two)

$\square$ Pensions are too complicated to do over the web

People will still want face to face explanations

Other (please specify below) $\square$ Lack of understanding of the Internet

Awaiting easier more accessible technology

- eg mobile phones and interactive television 
5.4 Will the internet have a bigger impact on the administration of pensions or on their communication? (Please state the reasons for your assessment in the space provided)

Administration

Communication

\section{Further comments and notes}

6.1 Please use this space to give us your thoughts on the use of the Internet in pensions or to modify or correct any of the answers you have given above.

Thank you for participating in this survey. 